\title{
AVALIAÇÃo DA ESTABILIDADE E DA QUALIDADE DO PATÊ DE PRESUNTO, ADICIONADO DE GLOBINA BOVINA E DE CASEINATO DE SÓDIO, COMO AGENTE EMULSIONANTE ${ }^{1}$
}

\author{
Janaina Guernica SILVA², Harriman Aley MORAIS², Roberto Gonçalves JUNQUEIRA², \\ Afonso de Liguori OLIVEIRA ${ }^{2}$, Marialice Pinto Coelho SILVESTRE ${ }^{3, *}$
}

\begin{abstract}
RESUMO
Este trabalho foi conduzido para avaliar o efeito da incorporação das globinas bovina extraída pelo método da acetona acidificada (GT) e pelo da carboximetilcelulose (GCMC) e do caseinato de sódio (CA) sobre a composição química e as qualidades microbiológica e sensorial do patê de presunto. Foi, ainda, avaliada a estabilidade do produto durante os 45 dias de estocagem sob refrigeração, por meio das determinações de pH e do grau de oxidação lipídica. De acordo com os resultados obtidos, pôde-se verificar que a adição dessas proteínas elevou o teor protéico das amostras analisadas. Além disso, observou-se que apenas a GT provocou uma queda do pH e uma elevação de substâncias reativas ao ácido 2-tiobarbitúrico (thiobarbiuric acid reactive substances - TBARS). Com relação à qualidade microbiológica dos produtos, não foram observadas alterações após a incorporação das proteínas e, pela análise sensorial, foram identificadas diferenças significativas entre as duas formulações de patê avaliadas (PCA e PGCMC).

Palavras-chave: globina bovina; caseinato de sódio; patê de presunto; oxidação lipídica; qualidade microbiológica; qualidade sensorial.
\end{abstract}

\section{SUMMARY}

STABILITY AND QUALITY OF HAM PATÉ ADDED OF BOVINE GLOBIN AND SODIUM CASEINATE AS EMULSIFIERS. This study evaluated the effect of the use of bovine globin extracted by acidified acetone method (GT), bovine globin extracted by carboxymethyl cellulose method (GCMC) and sodium caseinate (CA) on the chemical composition and on microbiological and sensorial qualities of the ham paté. Also, the stability of this meat product was studied during the storage for 45 days under refrigeration, on the $\mathrm{pH}$ and on the lipid oxidation measurements. An increase of the protein contents was observed in all samples. Moreover, only the incorporation of GT produced a significant decrease of $\mathrm{pH}$ and an increasing of thiobarbiuric acid reactive substances (TBARS) values during storage. No microbial effects were observed while some significant differences were observed between PCA and PGCMC added patés.

Keywords: bovine globin; sodium caseinate; ham paté; lipid oxidation; microbiological quality; sensorial quality.

\section{1 - INTRODUÇÃO}

O setor industrial e o de comercialização da carne no Brasil tem experimentado um crescimento contínuo nos últimos anos, sendo os derivados mais consumidos a salsicha, a mortadela e os patês de presunto e de frango [8]. Apesar de não serem emulsões verdadeiras, a qualidade destes produtos está fortemente associada a uma combinação de gordura, água e proteínas solúveis, as quais atuam como agentes emulsionantes. No processamento dos patês, o caseinato de sódio tem sido largamente empregado, por suas propriedades funcionais desejáveis, entretanto, são necessários grandes investimentos na obtenção desta matéria-prima, aumentando o custo da produção. As proteínas do sangue bovino podem, então, ser usadas como um substituto mais barato da caseína, uma vez que apresentam boas qualidade e propriedades emulsionantes [8, 9, 22].

Em estudos anteriores foram feitas a caracterização química e o estudo de algumas propriedades funcionais da caseína e da globina bovina $[6,7,18]$. O interesse desta etapa passou a se relacionar à incorporação destas proteínas, como agente emulsionante, a um deriva-

\footnotetext{
1. Recebido para publicação em 22/02/2000. Aceito para publicação em $07 / 06 / 2002$.

2. Departamento de Tecnologia e Inspeção de Produtos de Origem Animal - Escola de Veterinária - UFMG

3. Departamento de Alimentos - Faculdade de Farmácia - UFMG. Av. Olegário Maciel, 2360 / CEP: 30180-112 -Belo Horizonte, MG. Tel.: (31) 3339-7633 / Fax: (31) 3339-7666. E-mail: malice@farmacia.ufmg.br * A quem a correspondência deve ser enviada.
}

do de carne e à avaliação da sua qualidade, comparando-o com uma amostra, na qual não foi adicionado qualquer emulsionante.

Os patês estão sujeitos a vários fatores que influenciam a sua estabilidade e afetam sua vida-útil. Estes produtos se deterioram, principalmente, pelo crescimento microbiano e por reações químicas, reduzindo sua vidade-prateleira [17]. A oxidação lipídica é apontada como uma das principais causas desta deterioração, por alterar a qualidade sensorial, o valor nutritivo e a funcionalidade, afetando negativamente a aceitabilidade pelo consumidor. Devido à importância desta reação para a qualidade e estabilidade de carnes e derivados, a quantificação dos seus produtos secundários por diversos métodos, apresenta grande interesse para se avaliar a extensão destas modificações [15].

O objetivo deste trabalho foi o de avaliar o efeito da incorporação das globinas bovina e do caseinato de sódio sobre a composição química e as qualidades microbiológica e sensorial do patê de presunto. Foi, ainda, estudada a estabilidade, por meio das determinações de $\mathrm{pH}$ e da evolução da oxidação lipídica, pelo teste do TBA, após armazenamento das amostras sob refrigeração $\left(+4^{\circ} \mathrm{C}\right)$, por um período de até 45 dias.

\section{2 - MATERIAL E MÉTODOS}

\section{1 - Material}

O sangue bovino foi obtido de animais abatidos em frigorífico sob Inspeção Federal, na cidade de Igarapé 
(Minas Gerais). A carne utilizada na fabricação do patê foi adquirida no açougue de um hipermercado (Belo Horizonte, Minas Gerais). Os sais de cura e os condimentos, caseinato de sódio foram obtidos no mercado varejista de Belo Horizonte (Minas Gerais). As embalagens utilizadas para os patês consistiram de frascos de vidro com tampa, adquiridos no comércio de Belo Horizonte (Minas Gerais).

\section{2 - Métodos}

\subsection{1 - Extração do sangue bovino}

O sangue foi obtido de animais abatidos em Frigorífico sob Inspeção Federal. A globina bovina foi extraída pelos métodos da acetona acidificada [22] e da carboximetilcelulose [2], sendo denominadas, respectivamente, GT e GCMC.

\subsection{2 - Preparo dos patês de presunto}

Os patês de presunto acrescidos de globina bovina (PGT e PGCMC), caseinato de sódio (PCA) e o controle (PCO, sem emulsionante) foram produzidos em triplicata, no Laboratório de Bromatologia da Faculdade de Farmácia - UFMG, utilizando um mini-cutter (Sire, modelo Super cutter), segundo metodologia descrita por SILVA et al. [19], num total de 12 bateladas que foram autoclavadas a $121^{\circ} \mathrm{C}$ por $30 \mathrm{~min}$ (Figura 1). Três embalagens de cada batelada dos diferentes tipos de patê foram submetidas à análise microbiológica. As demais foram acondicionadas sob refrigeração $\left(+4^{\circ} \mathrm{C}\right)$ até o momento das análises.

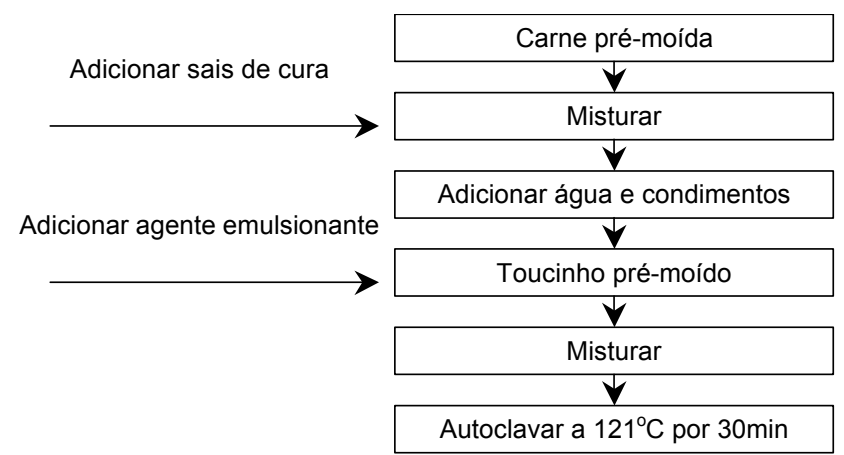

FIGURA 1. Fluxograma de produção do patê de presunto

\subsection{3 - Determinação da composição química dos patês de presunto}

A determinação dos teores de umidade, proteínas, lípides e cinzas dos PGT, PGCMC, PCA e PCO foi realizada de acordo com os métodos da AOAC [1]. Para avaliação do teor de ferro, utilizou-se os procedimentos analíticos para controle de produtos de origem animal [3].

\subsection{4 - Estudo da estabilidade dos patês de presunto}

Para estudo da estabilidade dos patês de presunto as amostras foram analisadas logo em seguida à esteri- lização (tempo zero), e após 7, 14, 21, 28 e 45 dias de armazenamento sob refrigeração a $4^{\circ} \mathrm{C}$ positivos.

\section{Determinação do pH}

$\mathrm{O}$ valor do $\mathrm{pH}$ das amostras de patê de presunto foi determinado pelo método da AOAC [1] utilizando-se potenciômetro Tecnal, modelo TCE-2.

\section{Avaliação da oxidação lipídica}

A quantidade de substâncias reativas ao ácido 2-tiobarbitúrico (thiobarbiuric acid reactive substances TBARS) foi determinada de acordo com o método descrito por ROSMINI et al. [16], utilizando-se tetrametoxipropano (TMP, Sigma Chemical Co.) como padrão e realizando-se algumas modificações, como a quantidade de amostra $(1,0 \mathrm{~g})$ e o volume dos reagentes. A absorbância foi lida a $532 \mathrm{~nm}$ em espectrofotômetro (UV-VIS - Cecil, modelo CE2041).

Inicialmente, foi calculada a taxa de recuperação do malonaldeído (MA) pela fórmula 1, seguindo a metodologia de SINNHUBER \& YU [20].

$\mathrm{RE}=\frac{\mathrm{A} 2-\mathrm{d}}{\mathrm{A} 1}$

na qual A2 = absorbância das amostras contendo $3 \times 10^{-8}$ moles de MA; A1 = absorbância das amostras sem MA e $\mathrm{d}=$ diferença entre A2 e A1.

Posteriormente, calculou-se a constante $\mathrm{K}$, seguindo o método de WITTE et al. [23], usando a fórmula 2:

$\mathrm{K}=\frac{\mathrm{S}}{\mathrm{A}} \times \mathrm{PM} \times \frac{10^{6}}{\mathrm{E}} \times \frac{100}{\mathrm{P}}$

na qual $\mathrm{S}=$ concentração do padrão $\left(3 \times 10^{-8}\right.$ moles de TMP $/ 5 \mathrm{~mL}) ; \mathrm{A}=$ absorbância do padrão; $\mathrm{PM}=$ peso molecular do TMP $(164,2) ; \mathrm{E}=$ amostra equivalente; e $\mathrm{P}=$ percentagem de recuperação do malonaldeído (MA).

Finalmente, encontraram-se os valores de TBARS que foram expressos em mg de malonaldeído (MA) por $\mathrm{kg}$ da amostra de patê de presunto, segundo a fórmula 3 .

K x Absorbância da amostra = mg de MA por kg da amostra (3)

\subsection{5 - Avaliação da qualidade microbiológica}

Os parâmetros analiticos, estabelecidos para produtos cárneos em geral, foram a inspeção externa das embalagens e a prova de esterilidade comercial, após incubação das amostras em suas próprias embalagens, por 10 dias a $35^{\circ} \mathrm{C}$, conforme o Decreto no 12.486 de 20/10/ 78 das NTA [13]. Todos os testes dos patês de presunto foram realizados em triplicata, segundo método recomendado pela INTERNACIONAL COMMISSION ON MICROBIOLOGICAL SPECIFICATIONS IN FOODS [12] e executados no Laboratório de Microbiologia de Alimentos da Divisão de Bromatologia e Toxicologia da Fundação Ezequiel Dias, Belo Horizonte, Minas Gerais. 


\subsection{6 - Análise sensorial}

A análise sensorial dos patês de presunto teve como objetivo avaliar se haviam diferenças detectáveis entre os patês de presunto em que foram incorporados a GCMC (PGCMC) e o CA (PCA). Esta análise foi realizada em duas etapas: a primeira, constou do treinamento dos 15 provadores e a segunda, da avaliação do conjunto de atributos sensoriais que determinam a qualidade global do produto.

\section{Treinamento dos provadores}

Esta etapa constou da apresentação dos patês de presunto, assim como da descrição dos objetivos da pesquisa e do método que seria utilizado durante a análise sensorial, a fim de melhor orientá-los quanto aos atributos mais importantes que seriam julgados para identificar as diferenças entre as amostras (cor, sabor, aroma e textura). Além disso, ficou definido que cada provador poderia diferenciar as amostras com base em um ou no conjunto dos atributos sensoriais considerados.

\section{Avaliação dos atributos sensoriais}

Foi utilizado o método descritivo pelo teste triangular para avaliação dos atributos sensoriais dos patês de presunto. A análise iniciou-se no quinto dia de armazenamento, sendo repetida no oitavo e décimo dias. No $5^{\circ}$ dia ( $1^{\text {a }}$ repetição) foi analisada a batelada 1 dos dois tipos de patês, no $8^{\circ}$ dia ( $2^{a}$ repetição) a 2 , e no décimo $\left(3^{a}\right.$ repetição) a 3 . Os provadores receberam três amostras de $30 \mathrm{~g}$ cada, e foram informados de que duas delas eram idênticas. A cada repetição, duas amostras de patê $A$ (PGCMC) e B (PCA), em arranjos AAB, ABA, ABB, BAA, $\mathrm{BAB}$ e $\mathrm{BBA}$ foram apresentadas aos provadores, e a eles foi solicitado analisá-las e identificar aquela formulação que era diferente, com base em um atributo sensorial específico (cor, sabor, aroma, textura) ou na qualidade global [5]. Foram consideradas corretas as respostas provenientes dos provadores que conseguiram identificar diferenças entre as amostras. De acordo com TEIXEIRA et al. [21] para o teste triangular, 9 é o número mínimo de seleções corretas, quando o número de julgadores é igual a 15 , para se considerar significativo a $5 \%$ de probabilidade.

\subsection{7 - Análise estatistica}

Para determinar variações entre a composição química dos diferentes tipos de patês, foi adotado a análise de variância, em delineamento inteiramente casualisado, para verificar a presença de efeitos significativos $(p<0,05)$ e, neste caso foi aplicado o teste de Duncan para determinar as diferenças entre as médias [14].

Para avaliar o efeito do tempo de armazenamento sobre os valores de TBARS e pH dos diferentes tipos de patês, foi adotado o delineamento experimental em parcelas subdivididas (no qual os tipos de patês foram as parcelas e o tempo de armazenamento as sub-parcelas) e análises de variância para determinar a existência de efeitos significativos ou interações entre os efeitos $(p<0,05)$. O teste de Duncan foi utilizado para determi- nar diferenças entre as médias, para os efeitos que se mostraram significativos pelo teste de F [14].

\section{3 - RESULTADOS E DISCUSSÃO}

\section{1 - Composição química dos patês de presunto}

Os resultados da composição química, apresentados na Tabela 1, indicam que os valores médios obtidos para os teores médios de umidade dos patês de presunto $(60,71)$ estão de acordo com a legislação brasileira [13], que estabeleceu no Decreto no 12.486 , de 20/10/ 78 , um limite máximo de $62 \%$. Verificou-se, ainda, nas amostras em que houve a incorporação das globinas bovina (GT e GCMC) e de caseinato de sódio (CA), um aumento de cerca de 3,0\% no teor protéico, confirmando as porcentagens adicionadas às formulações. Apesar do teor de ferro da GT $(757 \mathrm{mg} / \mathrm{kg})$ ser bem superior ao da GCMC (198mg/kg), como relatado na primeira parte deste trabalho, não foi observada diferença na quantidade deste elemento no produto final. Por outro lado, não foram encontradas diferenças nos teores de ferro entre o PGCMC, o PCA e o PCO.

TABELA 1. Composição química dos patês de presunto.

\begin{tabular}{cccccc}
\hline Tipos de & \multicolumn{4}{c}{$\mathrm{g} / 100 \mathrm{~g}^{2}$} & $\mathrm{mg} / \mathrm{Kg}^{2}$ \\
\cline { 2 - 6 } patês & Umidade & Lípides & Proteína & Minerai & Ferro \\
& & & $\mathrm{s}$ & $\mathrm{s}$ & \\
\hline PGT & $59,41^{\mathrm{a}}$ & $25,35^{\mathrm{a}}$ & $13,38^{\mathrm{a}}$ & $1,86^{\mathrm{a}}$ & $15,72^{\mathrm{a}}$ \\
PGCMC & $61,53^{\mathrm{a}}$ & $24,40^{\mathrm{a}}$ & $12,31^{\mathrm{a}}$ & $1,76^{\mathrm{a}}$ & $13,47^{\mathrm{a}, \mathrm{b}}$ \\
PCA & $59,29^{\mathrm{a}}$ & $25,06^{\mathrm{a}}$ & $13,22^{\mathrm{a}}$ & $1,76^{\mathrm{a}}$ & $12,16^{\mathrm{b}}$ \\
PCO & $61,96^{\mathrm{a}}$ & $25,34^{\mathrm{a}}$ & $10,90^{\mathrm{b}}$ & $1,80^{\mathrm{a}}$ & $11,6^{\mathrm{b}}$ \\
\hline
\end{tabular}

Apesar de não terem sido encontrados dados na literatura abordando a composição química do patê de presunto, alguns pesquisadores têm estudado outros derivados cárneos. Assim, um aumento do teor protéico foi observado, após a incorporação de diferentes proteínas em salsichas, tais como proteínas do germe de milho desengordurado [24], isolado comercial da globina bovina [10] e tecido conjuntivo bovino [4]. Quanto aos minerais no produto final, GUZMÁN et al. [9] relataram que em "cooked beef patties" (hambúrgueres pré-cozidos), a adição de um concentrado comercial de células vermelhas de sangue bovino descoloridas provocou uma elevação significativa dos niveis de íons ferro.

\section{2 - Estudo da estabilidade dos patês de presunto}

\subsection{1 - Acompanhamento por meio do $\mathrm{pH}$}

Observa-se na Tabela 2 que não houve alterações significativas nos valores de $\mathrm{pH}$ durante o período de armazenamento, para as 4 amostras de patês analisadas, sendo que para o PGT, ficou em torno de 5,00, enquanto que para os demais patês, próximo de 6,50 . A 
comparação com o controle (PCO) indica que, dentre as proteínas estudadas, apenas a incorporação da GT afetou o $\mathrm{pH}$ do patê de presunto, tendo provocado uma redução para todos os dias de armazenamento. Portanto, pode-se concluir que houve um certo comprometimento na estabilidade para as amostras contendo a GT $(4,82 \leq$ $\mathrm{pH} \leq 5,14)$, estando a mesma abaixo dos parâmetros estabelecidos pelas Normas Sanitárias do INSTITUTO ADOLF LUTZ [11], que consideram que o $\mathrm{pH}$ do patê ou pasta deve ser levemente ácido.

TABELA 2. Valores de $\mathrm{pH}$ dos patês de presunto $\left({ }^{*}\right)$, em função do tempo de armazenamento.

\begin{tabular}{ccccc}
\hline \multirow{2}{*}{$\begin{array}{c}\text { Tempo de } \\
\text { armazenamento } \\
\text { (dias) }\end{array}$} & PGT & PGCMC & PCA & PCO \\
\cline { 2 - 5 } & $5,14^{\mathrm{az}}$ & $6,52^{\mathrm{axy}}$ & $6,57^{\mathrm{ax}}$ & $6,48^{\mathrm{aby}}$ \\
7 & $5,03^{\mathrm{aby}}$ & $6,36^{\mathrm{bx}}$ & $6,37^{\mathrm{bx}}$ & $6,52^{\mathrm{abx}}$ \\
14 & $4,88^{\mathrm{cy}}$ & $6,45^{\mathrm{abx}}$ & $6,52^{\mathrm{ax}}$ & $6,46^{\mathrm{bx}}$ \\
21 & $4,93^{\mathrm{bcy}}$ & $6,45^{\mathrm{abx}}$ & $6,47^{\mathrm{abx}}$ & $6,61^{\mathrm{ax}}$ \\
28 & $4,84^{\mathrm{cy}}$ & $6,47^{\mathrm{abx}}$ & $6,46^{\mathrm{abx}}$ & $6,52^{\mathrm{abx}}$ \\
45 & $4,82^{\mathrm{cy}}$ & $6,36^{\mathrm{bx}}$ & $6,35^{\mathrm{bx}}$ & $6,45^{\mathrm{bx}}$ \\
\hline
\end{tabular}

Em alguns trabalhos realizados com salsichas foram apresentados resultados semelhantes aos obtidos com a GCMC e o CA uma vez que, durante o armazenamento das amostras por 30 a 45 dias, não foram observadas alterações nos valores de $\mathrm{pH}$ após a adição de proteínas diversas [4, 10, 24].

\subsection{2 - Acompanhamento por meio da oxidação lipidica}

Pelos dados apresentados na Figura 2, observa-se que dentre as quatro amostras analisadas, a oxidação lipídica foi mais acentuada para o PGT, ao longo do período de estudo, tendo atingido o máximo após 28 dias de armazenamento. Quando comparado ao controle, fica claro que apenas a incorporação da globina GT elevou significativamente as TBARS, dando origem a uma amostra de patê (PGT) susceptível a este tipo de alteração, durante todo o período de estocagem. Além disso, o aumento das TBARS é muito mais significativo para este patê com o tempo de armazenamento.

Estes resultados podem ser explicados pela presença de íons de ferro na globina GT, em quantidades elevadas $(757 \mathrm{ppm})$, como demonstrado na primeira parte deste trabalho, uma vez que todas as amostras têm a mesma formulação, variando-se apenas a proteína adicionada como agente emulsionante.

Não foram encontrados na literatura relatos sobre o estudo da evolução da oxidação lipídica em patês. Ao avaliar a estabilidade de salsichas, CALHOUN et al. [4] mostraram que, como os resultados de PGCMC e PCA, a adição de tecido conjuntivo bovino não alterou as TBARS durante um período de 45 dias de armazenamento. Por outro lado, um aumento significativo de TBARS foi veri- ficado por GUSMÁN et al. [9] ao avaliarem o efeito da adição de 2,25g / $100 \mathrm{~g}$ de um concentrado comercial de células vermelhas sobre esta reação química em hambúrgueres pré-cozidos, estocados por um período inferior a $24 \mathrm{~h}$. Como o método utilizado por estes autores para descoloração de células vermelhas se assemelha ao da acetona acidificada, pode-se dizer que estes resultados estão de acordo com os obtidos no presente estudo, uma vez que a adição de 3,0\% da GT ao patê de presunto (PGT) também elevou as TBARS desde o início do armazenamento.

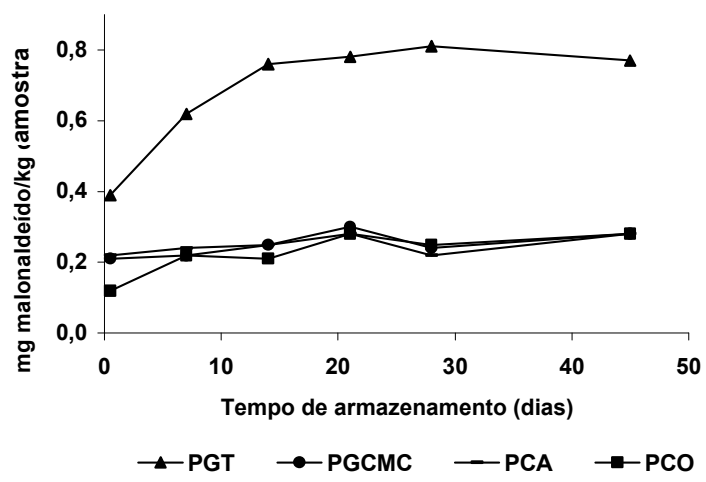

FIGURA 2. Efeito do tempo de armazenamento sobre os valores de substâncias reativas ao ácido 2-tiobarbitúrico (TBARS) dos quatro tipos de patês de presunto $($ PGT $=$ patê de presunto acrescido de globina bovina extraída pelo método da acetona acidificada; $\mathrm{PGCMC}=$ patê de presunto acrescido de globina bovina extraída pelo método da carboximetilcelulose; $\mathrm{PCA}=$ patê de presunto acrescido de caseinato de sódio; $\mathrm{PCO}$ = patê controle). Os valores representam médias de nove repetições (análise em triplicatas para as três bateladas)

\section{3 - Qualidade microbiológica}

De acordo com laudo técnico apresentado, para todas as amostras analisadas, não foram verificadas alterações nas embalagens de origem que apontassem o desenvolvimento de microrganismos capazes de comprometer o produto. Isto indica que, durante o preparo das amostras de patê, foram observadas as condições higiênicas necessárias à obtenção de um produto de boa qualidade microbiológica e que a incorporação das diferentes proteínas não afetou a microbiota do produto, nem sua estabilidade.

\section{4 - Análise sensorial}

De acordo com os dados apresentados na Figura 3, observa-se que a maioria dos provadores identificou corretamente a amostra diferente nos arranjos das formulações (PGCMC e PCA) apresentados. Assim sendo, podese afirmar que houve diferença na qualidade sensorial entre as amostras de patê contendo a GCMC e o CA.

Durante a avaliação, quatro provadores identificaram um sabor metálico e/ou de ranço na amostra PGCMC, principalmente, na 3a repetição, 10 dia de ar- 
mazenamento. Apesar da relação entre o sabor metálico e a rancidificação não ter sido confirmada pela diferença de TBARS (Figura 2) das amostras analisadas, não se pode afirmar que o PGCMC não esteja oxidado, uma vez que neste período (dia 10) a reação de oxidação lipídica está no início, não havendo, ainda, formação do malonaldeído. Assim, o sabor metálico detectado poderia estar relacionado com os produtos primários da reação não quantificados pelo teste do ácido 2tiobarbitúrico, e/ou com o próprio sabor da proteína GCMC, que contém 198mg/kg de Ferro, provavelmente detectado pelos provadores.

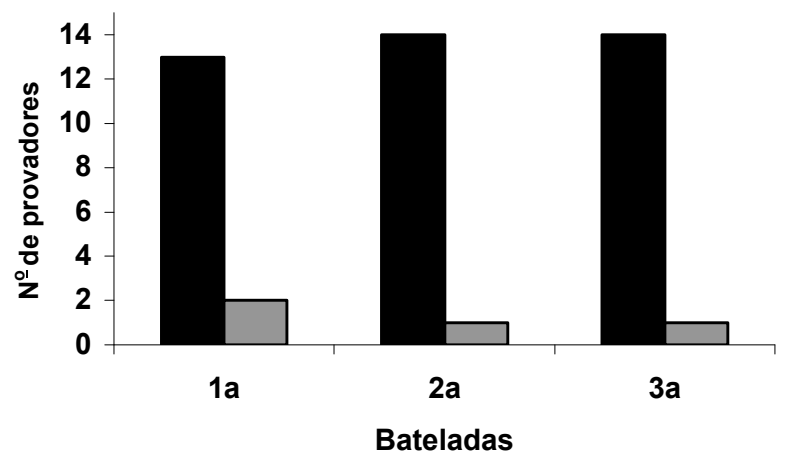

Respostas corretas $\square$ Respostas incorretas

FIGURA 3. Avaliação do número de respostas na análise sensorial das amostras de patê de presunto (respostas corretas = seleção correta da amostra diferente no arranjo apresentado e respostas incorretas $=$ seleção incorreta da amostra diferente no arranjo apresentado). Os valores representam o total de respostas julgadas por batelada

GUZMÁN et al. [9] também identificaram um flavor metálico pela análise sensorial de "cooked beef patties" (hambúrgueres pré-cozidos) acrescidos de um concentrado comercial de células vermelhas descoloridas, sendo relatado que esta alteração estava diretamente correlacionada com a quantidade de produto adicionado.

\section{4 - CONCLUSÕES}

Pode-se concluir que houve um aumento do teor protéico para todos os patês de presunto acrescidos das globinas bovina (PGT e PGCMC) e do caseinato de sódio (PCA). Além disso, a GT provocou uma redução dos valores de $\mathrm{pH}$, quando comparados ao controle, e um aumento significativo de TBARS, ao longo do armazenamento, sugerindo que essa proteína compromete a estabilidade do produto, tornando-o mais susceptivel à deterioração química. Pode-se verificar ainda que a incorporação da GCMC ou de caseinato de sódio não alterou a qualidade microbiológica nas amostras estudadas. Entretanto, estas proteínas deram origem a produtos cujas características sensoriais diferiram bastante entre si.

\section{5 - REFERÊNCIAS}

[1] AOAC (Association of Official Agricultural Chemists). Official methods of analysis of AOAC international. 16. ed. Arlington: AOAC International, 1995. $2 \mathrm{v}$.

[2] AUVINEN, J. Globin - a new functional protein for the food industry. Int. Food Ingred., v. 2, p. 10-13, 1992.

[3] BRASIL, Ministério da Agricultura, do Abastecimento e da Reforma Agrária. Secretaria Nacional de Defesa Agropecuária. Métodos analiticos oficiais para controle de produtos de origem animal. 2. rev. Brasília, 1992. Cap. 7. Determinação de traços de elementos (metais) em tecido animal. p. 47-49.

[4] CALHOUN, C.M., EILERT, S.J., MANDIGO, R.W. Connective tissue/acidic phosphate preblend effects on reduced fat frankfurters. J. Food Sci., v. 61, p. 459-464, 1996.

[5] CHAVES, J.B.P. Práticas de laboratório de análise sensorial de alimentos e bebidas. Viçosa: Universidade $\mathrm{Fe}-$ deral de Viçosa, p. 21-24, 1993.

[6] DUARTE, A. J.; CARREIRA, R. L.; JUNQUEIRA, R. G.; COELHO, J. V.; SILVESTRE, M. P. C. Propriedades emulsionantes e solubilidade da caseína bovina e de sus hidrolisados trípticos: 1. Efeito do $\mathrm{pH}$ e do tempo de hidrólise. Ciênc. Tecnol. Alimen., v. 18, n.3, p.295302, 1998a.

[7] DUARTE, A. J.; CARREIRA, R. L.; JUNQUEIRA, R. G.; COELHO, J. V.; SILVESTRE, M. P. C. Propriedades emulsionantes e solubilidade da caseína bovina e de sus hidrolisados trípticos: 2. Efeito da adição de $\mathrm{NaCl}$. Ciênc. Tecnol. Aliment., v. 18, n.3, p. 303-308, 1998b.

[8] GONÇALVES, J.R., SILVEIRA, E.T.F., YAMADA, E.A. Considerações sobre a utilização da pré-mistura no processamento de embutidos cárneos emulsionados. Colet. Inst. Tecnol. Aliment., v. 25, p.1-7, 1995.

[9] GUSMÁN, J.C., MCMILLIN, K.W., BIDNER, T.D., DUGASSIMS, S., GODBER, J.S. Texture, color and sensory characteristics of ground beef patties containing bovine blood proteins. J. Food Sci., v. 60, p. 657-660, 1995.

[10] HAZARIKA, M., BIRO, G. Effect of incorporation of blood proteins into sausage. J. Food Sci. Tech. Mys., v. 30, p. 380-381, 1993.

[11] IAL - Instituto Adolfo Lutz. Normas de qualidade de alimentos. São Paulo: Ofsanpan, 1967. v. 5, cdu: 664.92.10, 664.92.17, 664.92.111, 664.38

[12] ICMSF - International Commision on Microbiological Specification for Foods. Microrganims in foods. I. Their significance and methods of enumeration. 2. ed. ELLIOTT, R.P., CLARK, D.S., LEWIS, K.H., LUNDBECK, J.C.J., SIMONSEN, E. (Ed.). Toronto: University of Toronto Press, 1978. $434 \mathrm{p}$.

[13] NTA - Normas Técnicas Especiais Relativas a Alimentos. Decreto n. ${ }^{\circ} 12.486$, de 20 de outubro de 1978. MARTINS, P.E. (Ed). São Paulo: Secretaria do Estado de São Paulo, 1978. p. 153-164.

[14] PIMENTEL-GOMES, F. Curso de estatística experimental. 9. ed. Piracicaba: Nobel, 1981, 468 p.

[15] RAHARJOS, S., SOFOS, J.N. Methodology for measuring malonaldehyde as a product of lipid peroxidation in muscle tissues: a review. Meat Sci., v. 35, p. 145-169, 1993.

[16] ROSMINI, M.R. PERLO, F., PÉREZ-ALVAREZ, J.A., PAGÁNMORENO, M.J., GAGO-GAGO, A., LÓPEZ-SANTOVEÑA, F., ARANDA-CATALÁ, V. TBA test by an extractive method applied to paté. Meat Sci., v. 42, p. 103-110, 1996.

[17] SARANTÓPOULOS, C.I.G.L., PASSOS, R.B., DESTRO, M.T., SHIROSE, I. Estudo da estabilidade de salsicha embalada à vácuo e pasteurizada. Colet Inst. Tecnol. Aliment., 20, p. 184-193, 1990. 
[18] SILVA, J. G.; ORNELlAS, C. B. D.; CARVALHO, M. G.; JUNQUEIRA, R. G.; OLIVEIRA, A. L.; SILVESTRE, M. P. C. Caracterização química e funcional do caseinato de sódio e da globina bovina. Ciênc. Tecnol. Aliment., v. 20, n.2, p. 212-219, 2000a.

[19] SILVA, J. G.; JUNQUEIRA, R. G.; OLIVEIRA, A. L.; SILVESTRE, M. P. C. Incorporação da globina bovina e do caseinato de sódio como agente emulsionante do patê de presunto. Braz. J. Food Technol., v. 3, p. 115-120, 2000b.

[20] SINNHUBER, R.O., YU, T.C. 2-Thiobarbituric acid method for measurement of rancidity in fishery products. II. The quantitative determination of malonaldehyde. Food Technol., v. 12, p. 9-12, 1958.

[21] TEIXEIRA, E., MEINERT, E.M., BARBETTA, P.A. Análise sensorial de alimentos. Florianópolis: Editora da Universidade Federal de Santa Catarina, 1987. 180 p.

[22] TYBOR, P.T., DILL, C.W., LANDMANN, W.A. Effect of descolorization and lactose incorporation on the emulsification capacity of spray-dried blood protein concentrates. J. Food Sci., v. 38, p. 4-6, 1973.

[23] WITTE, V.C., KRAUSE, G.F., BAILEY, M.E. A new extraction method for determining 2-thiobarbituric acid values of pork and beef during storage. J. Food Sci., v. 35, p. 582-585, 1970.

[24] ZAYAS, J.F., LIN, C.S. Effect of the pretreatment of corn germ protein on the quality characteristics of frankfurters. J. Food Sci., v. 54, p. 1452-1456, 1989.

\section{6 - AGRADECIMENTOS}

Os autores agradecem à Josélia Maria de Souza e a Profa. Lúcia Helena E. L. dos Santos pela grande contribuição nas análises microbiológicas e sensorial, realizadas neste estudo e ao CNPq pelo oferecimento de recursos sob a forma de bolsas e à FAPEMIG, pelo apoio financeiro. 